\title{
STUDY OF THE PERFORMANCE OF AN ELECTRICALLY PROPELLED VEHICLE MAKING USE OF PID CONTROLLER
}

\author{
N.K.Mandal ${ }^{1}$, Silajit Ghosh ${ }^{2}$, Shubham Chatterjee ${ }^{3}$, Spandan Ghosh ${ }^{4}$, Md.Towfik Rahaman ${ }^{5}$
}

Abstract: Theoretical studies have been carried out to find the performance of an electrically propelled vehicle system such as electric bus, making use of a PID controller. For these studies, transfer function and hence gain of the system and frequency response using MATLAB have been found out. Study has also been done to determine steady state errors of the system for different types of input signals such as -unit step, unit ramp and unit parabolic.

Results have been tabulated graphically shown and discussed.

Keywords: Electrically propelled car; PID controller; frequency response; steady state errors.

\section{INTRODUCTION}

Electrically propelled vehicles, like-battery driven bus, auto-rickshaw etc. have been given due importance instead of engine driven vehicles for the last many years [1,2]. This is due to the fact that

1. They help in controlling environmental pollution.

2. They are clean and hygienic

3. They do not use engine which makes use of pollution making oil.

4. They can operate easily by electrically braking and stopping.

5. They make use of chargeable battery which has less maintenance cost compare to internal combustion engine. Various types of electrical feedback systems are widely used in different fields. But for the smooth operation of the system, a PID controller is preferred compare to the other controllers such proportional, derivative. Integral controllers and combination of them. In this paper, an attempt has been made to study the performance of an electric bus making use of a PID controller to monitor its operation.

\section{INSTRUMENTATION SYSTEM AND METHOD}

The block diagram model of electrically propelled vehicle with a PID controller is shown in the fig:

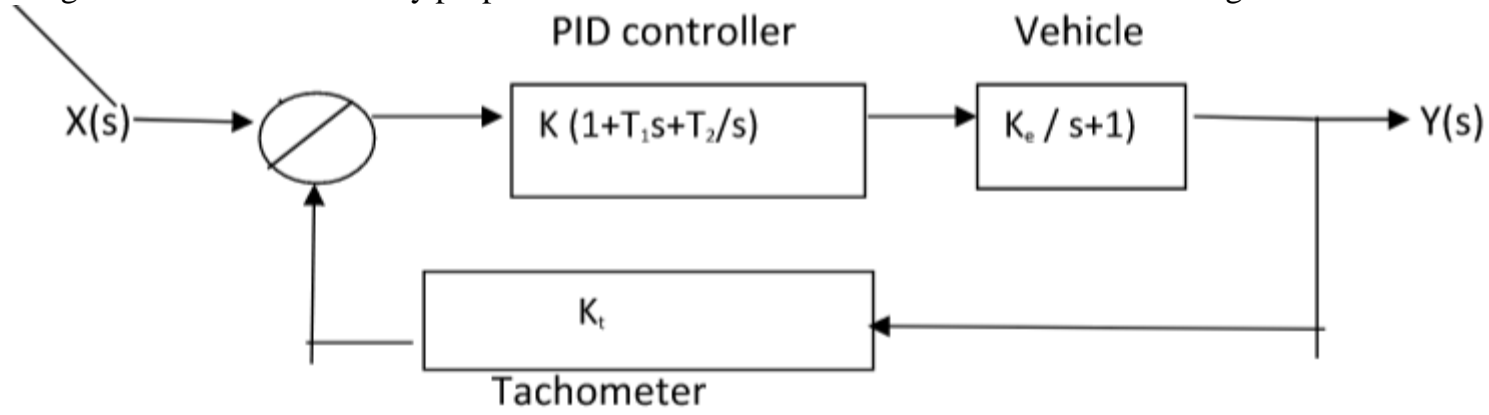

Fig.1: Block diagram model of electrically propelled car with PID controller.

The system consists of a battery operated electric bus whose operation is monitor by PID controller. The tachometer is used to control speed. The input signal applied may be unite step, unit ramp or unit parabolic. The tachometer provides the feedback electrical signal. The comparator is used to compare desired output signal and feedback signal.

\subsection{Analysis}

1. For analysis following assumptions have been made.

2. The battery operated vehicle is an electric bus.

3. Electric braking system is used to stop it or to control its speed.

Tachometer constant $(\mathrm{Kt})$ is unity.

The analysis of the system is done to find:-

a) The transfer function of the whole system,

1,2,3,4,5 Department of Electrical Engineering, University of Engineering \& Management, Kolkata, India 
b) Overall gain of the system.

c) Frequency response of the system by developing a program using MATLAB ,and

d) Steady state errors due to applications of input signals, such as unit step, unit ramp and unit parabolic.

\subsubsection{Determination of overall transfer function of the system}

To obtain the overall transfer function of the system, let us consider the block diagram model as shown in fig.1. The closed loop transfer function of the same can be expressed as

$\mathrm{A}(\mathrm{s})=\mathrm{Y}(\mathrm{s}) / \mathrm{X}(\mathrm{s})=(\mathrm{K} \mathrm{Ke}(\mathrm{T} 1 \mathrm{~s} 2+\mathrm{s}+\mathrm{T} 2)) /((\mathrm{K} \mathrm{KeKt} \mathrm{T}+2) \mathrm{s} 2+(\mathrm{K} \mathrm{KeKt}+1) \mathrm{s}+\mathrm{KKeKtT} 2)$

Where, $\mathrm{X}(\mathrm{s})=$ Input signal

$\mathrm{Y}(\mathrm{s})=$ Output signal

$\mathrm{K}=$ Proportional constant

$\mathrm{T}_{1}=$ Derivative constant

$\mathrm{T}_{2}=$ Integral constant

$\mathrm{K}_{\mathrm{e}}=$ Electric vehicle constant

$\mathrm{K}_{\mathrm{t}}=$ Tachometer constant

\subsubsection{Determinationof the overall gain of the system}

At $\mathrm{s}=\mathrm{j} \omega$, the equation (1.) can be expressed as:-

$A(j \omega)=(K \operatorname{Ke}[(T 2-T 1 \omega 2)+j \omega]) /([M T 2-\omega 2(M T 1+2)]+j(M+1) \omega)$

Where $\mathrm{M}=\mathrm{K} \mathrm{Ke} \mathrm{Kt}$

The gain of the system in $\mathrm{db}$ can be written as

$\mathrm{G}=20 \log |\mathrm{M}(\mathrm{j} \omega)|$

$=20 \log (\mathrm{K} \mathrm{Ke}[(\mathrm{T} 2-\mathrm{T} 1 \omega 2) 2+\omega 2] 1 / 2 /[\mathrm{MT} 2-\omega 2(\mathrm{MT} 1+2)] 2+(\mathrm{M}+1) 2 \omega 2] 1 / 2$

Using equations the frequency response of the system can be obtained at different values of $\omega$. The MATLAB program has been developed to find the same as described in the next section.

2.1.3 MATLAB programme to find frequency response of the system

$\mathrm{A}(\mathrm{s})=\mathrm{Y}(\mathrm{s}) / \mathrm{X}(\mathrm{s})=(\mathrm{K} \mathrm{Ke}(\mathrm{T} 1 \mathrm{~s} 2+\mathrm{s}+\mathrm{T} 2)) /((\mathrm{K} \mathrm{KeKt} \mathrm{T}+2) \mathrm{s} 2+(\mathrm{K} \mathrm{KeKt}+1) \mathrm{s}+\mathrm{K} \mathrm{t} \mathrm{KeKT} 2)$

$\mathrm{Ke}=20, \mathrm{~K}=1, \mathrm{~T} 1=1, \mathrm{~T} 2=1, \mathrm{Kt}=1$

$\mathrm{A}(\mathrm{s})=20(\mathrm{~s} 2+\mathrm{s}+1) / 22 \mathrm{~s} 2+21 \mathrm{~s}+20$

MATLAB command:

$\mathrm{A}=\mathrm{tf}\left(\left[\begin{array}{lll}20 & 20 & 20\end{array}\right],\left[\begin{array}{lll}22 & 21 & 20\end{array}\right)\right.$;

bode(A)

\subsubsection{Determination of a steady state error}

By examining the block diagram model as shown in the fig1. The open loop transfer function with PID controller can be expressed as

$\mathrm{G}(\mathrm{s})=\mathrm{K} \mathrm{Ke}(1+\mathrm{T} 1 \mathrm{~s}+\mathrm{T} 2 / \mathrm{s}) /[\mathrm{s}+1]$

The error signal is

$\operatorname{Er}(\mathrm{s})=\mathrm{X}(\mathrm{s}) /[1+\mathrm{g}(\mathrm{s}) \mathrm{h}(\mathrm{s})]$

$=(2 \mathrm{~s}+1) \mathrm{X}(\mathrm{s}) /(\mathrm{K} \mathrm{Ke} \mathrm{Kt}(1+\mathrm{T} 1 \mathrm{~s}+\mathrm{T} 2 \mathrm{~s}))$

The steady state error of the system can be expressed as:_

Ess $=$ Limit $(2 \mathrm{~s}+1) \mathrm{K}(\mathrm{s}) /(\mathrm{K} \mathrm{Ke} \mathrm{Kt}(1+\mathrm{T} 1 \mathrm{~s}+\mathrm{T} 2 / \mathrm{s}))$

s0

The test signals that can be used for calculations of steady state error are:-

1.) Limit step: $X(s)=1 / s$

2.) Unit ramp input: $X(s)=1 / s 2$

3.) Unit parabolic input: $X(s)=1 / s 3$

\section{RESULTS AND DISCUSSION}

The data obtained after the analysis of electrically propelled bus with PUD controler,can be used to study its performance by calculating the steady state errors and obtaining the nature of frequency response.

Table-1 : Determination of steady state error:-

\begin{tabular}{|l|l|l|}
\hline Type Of Controller & Type Of Signal Used & Steady State Error \\
\hline Pid & A) Unit Step & 0 \\
\hline & B) Unit Ramp & $1 /$ Ke Kt T2 \\
\hline & C) Unit Parabolic & $\infty$ \\
\hline
\end{tabular}


It can be seen from the TABLE-1 that steady state error is zero for unit step excitation. This is possible for an ideal case only. But for a practical system, there will be always some errors. For unit ramp input, the steady state error of the system, depends on the values of $\mathrm{K}, \mathrm{Ke}, \mathrm{Kt}$ and $\mathrm{T} 2$. So in case, the value of steady error can be controlled by adjusting the values of $\mathrm{K}, \mathrm{Ke}, \mathrm{Kt}$ and T2. Again, the steady state error of the system is infinite for unit parabolic input signal. So this signal cannot be applied or not suitable for the system.

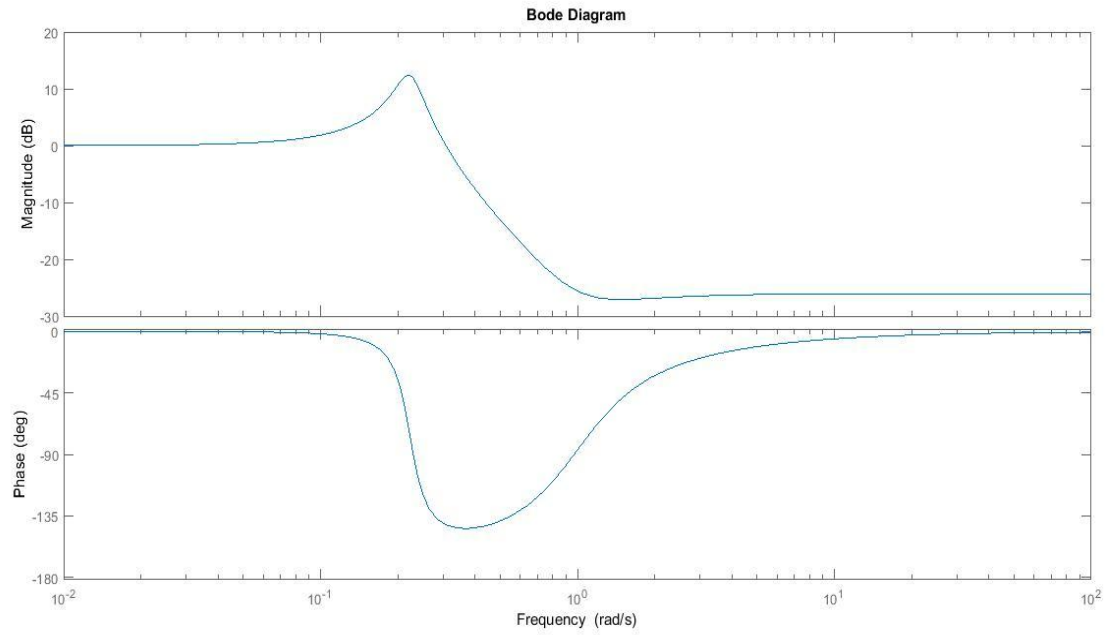

Fig.2: Frequency response of the system

It has stable gain of $-26 \mathrm{~dB}$ in the range of $\omega=1 \mathrm{rad} / \mathrm{sec}$ and above.it can also be seen that the phase angle of system is zero degree in the ranges $\omega=0.01 \mathrm{rad} / \mathrm{sec}$ to $0.1 \mathrm{rad} / \mathrm{sec}$ and $\omega=3 \mathrm{rad} / \mathrm{sec}$ and above.

\section{CONCLUSION}

In this investigation, we have studied the performance of a electrically propelled vehicle theoretically. But the actual performance can be obtained by designing such system and doing some experiments.

In this case we have considered the action of PID controller only. But results will vary, if we choose other types of control action such as proportional, derivative, integral or combination of them. The results will also vary if we consider other values of $\mathrm{K}, \mathrm{Ke}, \mathrm{Kt}, \mathrm{T} 1$ and $\mathrm{T} 2$.

\section{REFERENCES}

[1] Nagrath I.J and Gopal M.control system engineering, 4th edition, new age international publisher(2005).

[2] Ogata K. modern control engineering. Prenctice hall englewood cliffs,NJ,2 nd edition[1995].

[3] Close C.M and Frederick,modelling and analysis of dynamic system,rtonseton_miffin,boston,2nd edition(1993).

[4] Cheng K.W.E. ' Recent Development in Electrical Vehicle'.IEEE Explore (2009).

[5] Mohmoudi Choki, Flash Aymen and Sabita Lassad. 'Overview of Development of Electrical Vehicle concept and Power Management'. IEEE Explore (2014) 